\title{
Seismic Response of Multistoried Building Considering Effect of Cohesive and Non-Cohesive Soil
}

\author{
Aniket S. Deshmukh ${ }^{1}$, Dr. Tushar G. Shende ${ }^{2}$ \\ ${ }^{1}$ M.TECH, Structural Engineering, GHRAET, Nagpur, Maharashtra, India \\ ${ }^{2}$ Head of Civil Engineering Department of GHRAET, Nagpur, Maharashtra, India
}

\begin{abstract}
The response of a structure under earthquake loading is directly associated with the response of soil to ground shaking. Thus, the extent and degree of damage during an earthquake is mainly influenced by the response of soil to ground vibrations. Therefore, it is vital to evaluate the response of soil due to ground vibration. Though the structures are supported on soil, most of the designers do not consider the soil structure interaction and its subsequent effect on structure during an earthquake. Different soil properties can affect seismic waves as they pass through a soil layer. When a structure is subjected to an earthquake excitation, it interacts the foundation and soil, and thus changes the motion of the ground. It means that the movement of the whole ground structure system is influenced by type of soil as well as by the type of structure. The present study is an effort towards analysis of the structure during the earthquake. G+10 stories residential building is considered. To study various parameters such as shear force, bending moment, storey drifts, storey shear, lateral displacement.
\end{abstract} Keywords : Cohesive and Non-Cohesive Soil, Soil-Structure Interaction (SSI), Time History Method.

\section{INTRODUCTION}

The procedure in which the action of soil imparts the movement of the structure and the movement of the structure affects the action of the soil is called as SSI. Impendence difference is characterized as result of speed and thickness of soil. Seismic wave ventures quicker in hard shakes in contrasted with milder shakes and silt. As the waves goes from harder to milder rocks, they turn out to be moderate and should get greater in abundance to convey the same measure of the energy, in this way shaking tends to more grounded at sides with gentler surface layers, where seismic waves move more gradually. Resonance obtained when signal frequency matches with fundamental frequency of soil, they say that in resonance with one another, this results in to tremendous increase in ground motion amplification. Irregular basement topography when subjects to body wave incidence results in focusing and defocussing effect. This strongly depends on angle of incidence wave. The impact on a structure during an earth quake relies upon the properties of the ground soil, intensity of earth quake and structural system. When the foundation is on firm ground the foundation motion is basically taken at the soil level with the absence of structural system. For foundation on soft soil foundation motion varies from that in the free field due to the coupling of soil and structure during earth quake this is due to the scattering of waves and energy released due to the vibration of structures. Due to these impacts the condition of displacements in the supporting soil is different from free field because of these dynamic response of a structure is differ greatly in amplitude and frequency. Cohesive soil means soil with a high clay content, which has cohesive strength. Cohesive soil does not crumble, can significant cohesion when submerged. 
Cohesive soils include clayey silt, sandy clay, silty clay, clay and organic clay be excavated with vertical side slopes and is plastic when moist. Cohesive soil is hard to break up when dry and exhibit Composition, Cohesion and Consistence. In the present study various field penetration tests were conducted on cohesive and non-cohesive soils and design the optimum size of the footing based on the field tests.

Soil-structure interaction (SSI) analysis evaluates the collective response of three linked systems: the structure, the foundation, and the soil underlying and surrounding the foundation. Problems associated with practical application of SSI for building structures are rooted in a poor understanding of fundamental SSI principles. Implementation in practice is hindered by a literature that is difficult to understand, and codes and standards that contain limited guidance. It provides a synthesis of the body of SSI literature, distilled into a concise narrative, and harmonized under a consistent set of variables and units. Techniques are described by which SSI phenomena can be simulated in engineering practice, and specific recommendations for modeling seismic soil-structure interaction effects on building structures are provided.

Observations from past earthquakes of failure of structures.

Fig.1.1 shows a remarkable ground failure occurred near the Shinano river bank where the multistoried apartment buildings suffered bearing capacity failures and tilted severely. In Fig (1.2), sand boils and ground fissures were observed at various sites in Niigata, lateral spreading caused the foundations to move laterally so much that the simply supported spans became unseated and collapsed.

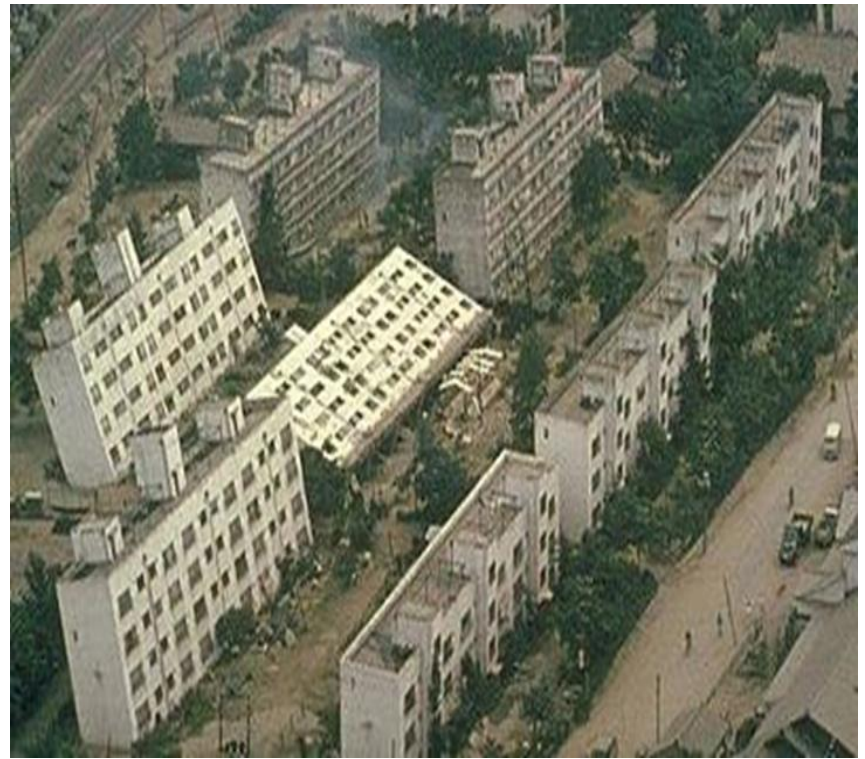

Fig.1.1 Failure of multistoried buildings during Niigata earthquake (1964), a city located on Sad island, in the Chūbu region of Japan.

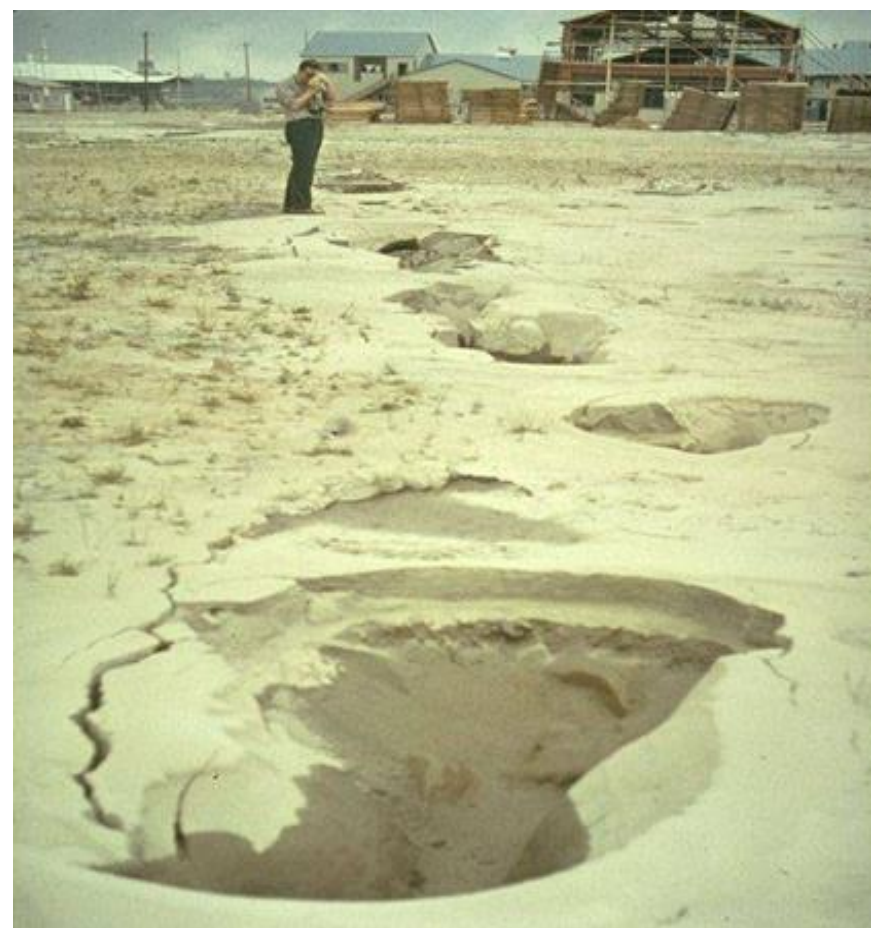

Fig.1.2 A remarkable ground failure occurred near the Shinano river bank in Niigata earthquake 


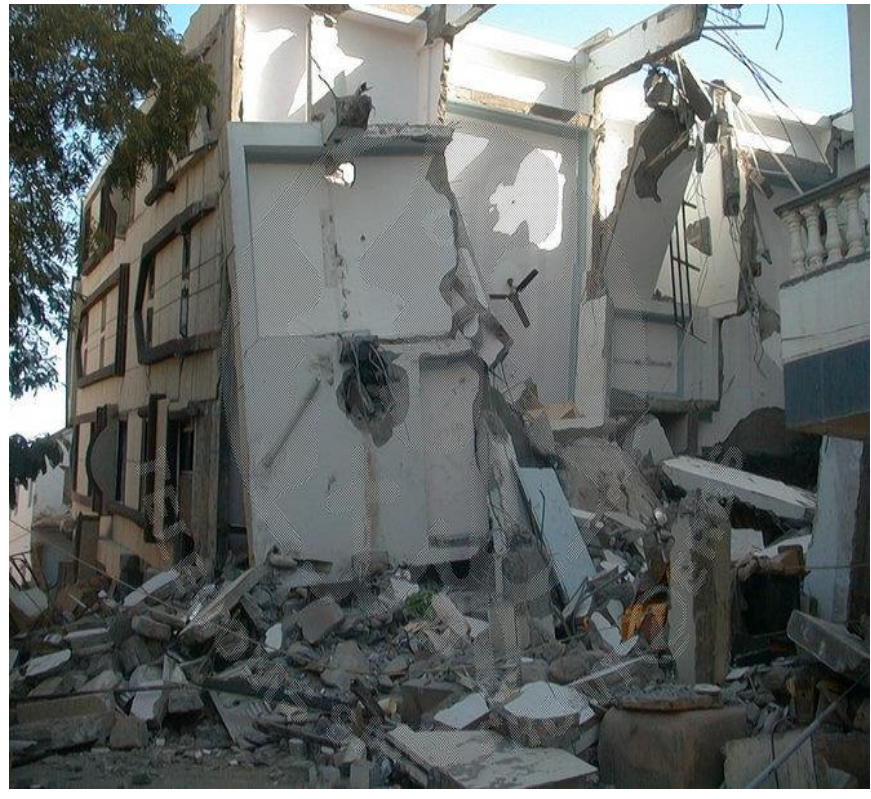

Fig.1.3 Bhuj (Jan 26, 2001) earthquake, in Gujrat,

India.

Reinforced concrete buildings have been damaged on a very large scale in Bhuj earthquake of Jan 26, 2001 (Fig.1.3).These buildings have been damaged due to various reasons. Identification of a single cause of damage to buildings is not possible. There are combined reasons, which are responsible for multiple damages. This is because of seismic action and inelastic response of structures. The principal causes of destruction to buildings are soft stories, floating columns, mass irregularities, poor quality of material, faulty construction practices, inconsistent seismic performance of soil, foundation effect, pounding of adjacent structures and inadequate ductile detailing in structural components.

The present study is an effort towards analysis of the structure during the earthquake. G+10 stories residential building is considered. To study various parameters such as shear force, bending moment, storey drifts, storey shear, lateral displacement, four models as mentioned below are considered.

Model I: Building with fixed base on cohesive soil.
* Model II: Building with fixed base on noncohesive soil.

* Model III: Building with SSI on cohesive soil.

* Model IV: Building with SSI on non-cohesive soil.

For all the models mentioned above the base shear result are compared.

\section{OBJECTIVES}

The main aim of this project is to generate fundamental research information on the seismic performance of building structural systems having cohesive and non-cohesive soil media.

* The structure should withstand the moderate earthquakes, which may be expected to occur during the service life of structure with damage within acceptable limits.

* Create computer models of building with fixed base for cohesive and non-cohesive soil.

* Create computer models of building with soil interaction.

* To study the seismic performance of the regular building for different types of soils.

* To study the seismic performance of the regular building for fixed base and soil interaction.

* To analyze the displacement of the structure along different direction by using time history method.

* Various static checks are applied on the results.

* Study the effect of important parameters such as base shear and lateral displacement.

* Use the research to find axial force and moments in columns and shear and moments in beams.

\section{METHODOLOGY}

From the previous chapter, it has been decided to proceed with Time history analysis for finding the 
seismic response of the building. This study deals with the seismic performance of $\mathrm{G}+10$ storey building in cohesive and non-cohesive soil media for seismic zones III of India. Total four models are made for analysis of building. Seismic analysis is done by time history method.

This chapter explains the Indian standard codes guidelines for the analysis of such structures, study the suitability of fixed base and soil structure interaction (SSI). Building is modeled and analyzed for earthquake forces as per IS1893:2016 guidelines for Indian Seismic zone III. Also the seismic analysis of building is done by using time history method using FEM Software ETAB 2016.

\subsection{Analytical Model}

In this section, the detailed procedure of Time history analysis and parameters to be considered are explained for building model according to IS 1893 (Part 1): 2016

\subsubsection{Considerable Parameters}

Historically, seismic loads were taken as equivalent static accelerations which were modified by various factors, depending on the location's seismicity, its soil properties, the natural frequency of the structure, and its intended use. The method was refined over the years to enable increasingly adequate designs. The underlying design philosophy was basically unchanged; some modifications were made to the coefficients as a result of strong earthquakes. Other modifications to account for new information were introduced by specifying acceptable structural details for different construction materials.

(a) Seismic zone factor, Z: India has been divided into four seismic zones as per IS 1893 (Part 1): 2016 for the Maximum Considered Earthquake (MCE) and service life of the structure in a zone. Different zone have different zone factor. India is divided into four seismic zones. There are three types of soil considered by IS 1893 (Part 1): 2016 i.e. soft, medium and hard soil.

TABLE 3.1: ZONE FACTOR (IS1893-2016)

\begin{tabular}{|l|l|l|l|l|}
\hline $\begin{array}{l}\text { Seismic } \\
\text { Zone }\end{array}$ & II & III & IV & V \\
\hline $\begin{array}{l}\text { Seismic } \\
\text { intensity }\end{array}$ & Low & Moderate & Severe & $\begin{array}{c}\text { Very } \\
\text { Sever } \\
\text { e }\end{array}$ \\
\hline Z & 0.10 & 0.16 & 0.24 & 0.36 \\
\hline
\end{tabular}

b) Seismic weight of the floors: For calculation of design seismic forces of building, imposed load on roof need not be considered. But, weight of equipment and other permanently fixed facilities should be considered in such a case the reduction of imposed loads mentioned in Table 3.2

TABLE 3.2: PERCENTAGE OF IMPOSED LOADS TO BE CONSIDERED SEISMIC WEIGHT (IS18932016)

\begin{tabular}{|c|c|}
\hline $\begin{array}{l}\text { Imposed uniformity distributed } \\
\text { floor loads }\left(\mathrm{kN} / \mathrm{m}^{2}\right)\end{array}$ & $\begin{array}{l}\text { Percentage } \\
\text { of imposed } \\
\text { load }\end{array}$ \\
\hline Up to and including 3.0 & 25 \\
\hline Above 3.0 & 50 \\
\hline
\end{tabular}

c) Design Seismic Base Shear:-The total design lateral force or design seismic base shear (VB) along any principal direction shall be determined by the following expression:

$$
V_{B}=A_{h} W
$$


Where,

$\mathrm{A}_{\mathrm{h}}$ - Design horizontal acceleration spectrum value as per clause 6.4 .2 of IS 1893-2016, using the fundamental natural period $\mathrm{T}$, in the considered direction of vibration, and

W - Seismic weight of the building.

d) Design Spectrum:- For the purpose of determining seismic forces, the country is classified into four seismic zones the design horizontal seismic coefficient Ah for a structure shall be determined by the following expression:

$$
A_{h}=\frac{z}{2} \times \frac{s_{a}}{g} \times \frac{I}{R}
$$

Where,

$\mathrm{Z}$ - Zone factor (The factor 2 in the denominator of $\mathrm{Z}$ is used so as to reduce the Maximum Considered Earthquake (MCE) zone factor to the factor for Design Basis Earthquake (DBE).)

I - Importance factor.

$\mathrm{R}$ - Response reduction factor.

$\mathrm{S}_{\mathrm{a}} / \mathrm{g}$ - Average response acceleration coefficient

e) Structural response factor, $(\mathrm{Sa} / \mathrm{g})$ :

It is a factor denoting acceleration response spectrum of the structure subjected to earthquake ground vibrations, and depends on natural period of vibration and damping of the structure.

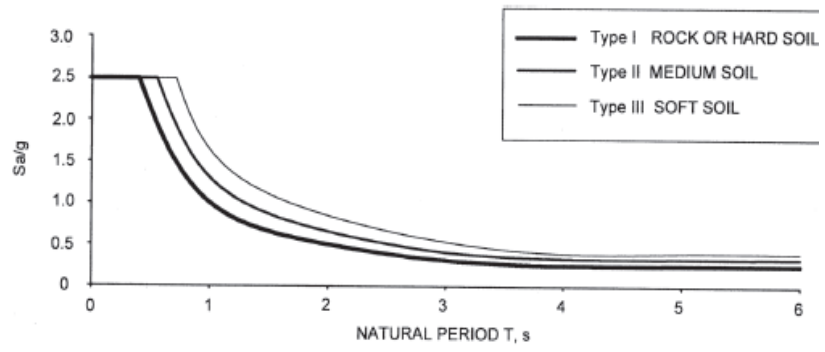

Figure 3.1: Spectra for equivalent static method

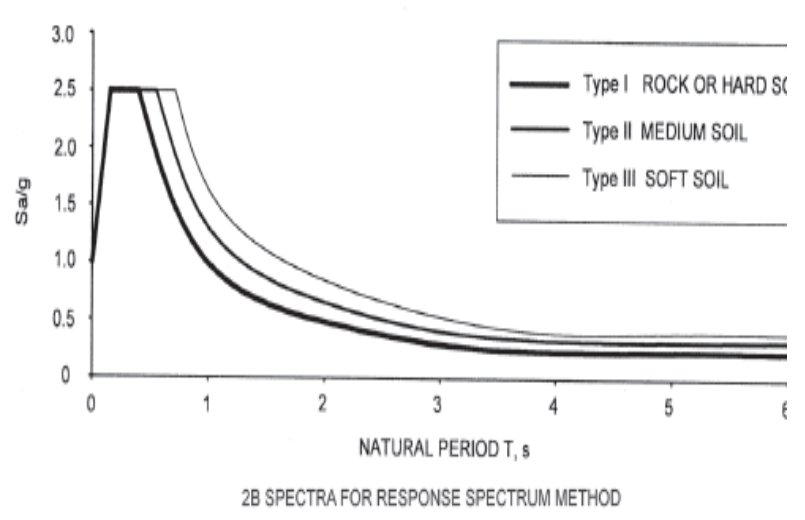

Figure 3.2: Spectra for response spectrum method

\subsection{Load combinations as per IS 1893:2016 (part 1)} For the analysis following load combinations specified by the IS 1893: 2016 are used. The basic load combinations given by the code as per clause 6.3.4.1 are as follows

1. $1.2(\mathrm{DL}+\mathrm{LL} \pm(\mathrm{EQX} \pm 0.3 \mathrm{EQY} \pm 0.3 \mathrm{EQZ}))$

2. $1.2(\mathrm{DL}+\mathrm{LL} \pm(\mathrm{EQY} \pm 0.3 \mathrm{EQX} \pm 0.3 \mathrm{EQZ}))$

3. $1.5(\mathrm{DL} \pm(\mathrm{EQX} \pm 0.3 \mathrm{EQY} \pm 0.3 \mathrm{EQZ}))$

4. $1.5(\mathrm{DL} \pm(\mathrm{EQY} \pm 0.3 \mathrm{EQX} \pm 0.3 \mathrm{EQZ})$

5. $\quad 0.9 \mathrm{DL} \pm 1.5(\mathrm{EQX} \pm 0.3 \mathrm{EQY} \pm 0.3 \mathrm{EQZ})$

6. $0.9 \mathrm{DL} \pm 1.5(\mathrm{EQY} \pm 0.3 \mathrm{EQX} \pm 0.3 \mathrm{EQZ})$

\subsection{Time History Analysis}

The basic idea of time-history analysis is to reproduce the actual behavior of a structure under the action of ground motions. The time history analyses technique represents the most sophisticated method of dynamic analysis for structures. In this method, the mathematical model of the structure is subjected to acceleration from earthquake records that represent the expected earthquake at the base of the structure. Time history method consists of a step by step direct integration over a time interval; the equation of motion are solved with the displacements, velocities and acceleration of the previous step serving as initial function. For that selected earthquake ground motions are considered as an input motion for time history analysis and applied at the base of structure. 
The seismic performance of structure under selected earthquake records has been examined in severe load combination condition.

\subsection{Inputs Ground Motions and Analysis Procedure}

The horizontal component of "EL-Centro" earthquake ground motion is chosen for time history analysis. The details of the ground motion like PGA and recording station is presented in graph the ground motion are applied along the $\mathrm{X}$ direction. The time history analysis in ETAAB 2016 was performed. The present study adopts the time history analysis which is the most accurate method available to get the seismic response of a structure. In this method, structure's response history is evaluated by subjecting it to a ground motion corresponding to the zone III of IS code 1893 design spectrum with peak ground acceleration of $0.09 \mathrm{~g}$. The duration of the earthquake is 30 seconds. Time history of acceleration was applied in the global $\mathrm{X}$ direction of the entire soilstructure model. The analysis was carried out for each incremental time interval and at each stage structural response was evaluated. ETAB 2016 finite element software was used for the time history analysis. The material damping ratio was assumed as $5 \%$ for structure.

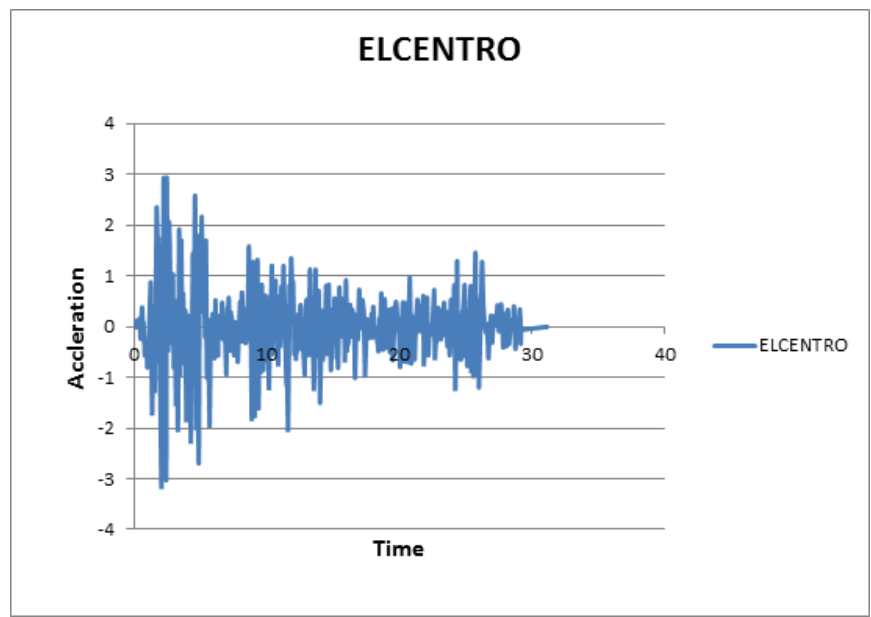

Figure 3.3 Graph showing El-Centro ground motion data up to $30 \mathrm{sec}$

\subsection{Soil Idealization}

At prsent Soil Structure Interaction is a standout amongst the most thriving zones of exploration in Structural Engineering. It can be characterized as the coupling between structures and its supporting medium (bedrock or soil bed) during an earthquake. Tackling such problems has become possible lately due to a revolution in computer technology. Works done in the late decade have demonstrated the significance of structure-soil structure interaction on the dynamic response of key structures such as silos, storage tanks, and offshore structures. Hence SSI calls for improvement in Codal provisions for the seismic design and communications between geotechnical and structural engineers. Compared with the counterpart fixed-base system, SSI has two basic effects on structural response. Firstly, the SSI system has an increased number of degrees of freedom and thus modified dynamic characteristics. Secondly, a significant part of the vibration energy of the SSI system may be dissipated either by radiation waves, emanating from the vibrating foundation-structure system back into the soil, or by hysteretic material damping in the soil. The result is that SSI systems have longer natural periods of vibration than their fixed-base counterparts.

To examine the structure-foundation- soil system, soil is treated as a homogenous, isotropic and elastic half space medium. The inputs considered for the linear analysis of structure are density of soil, Young's modulus (Es) and Poisson's ratio $(\mu)$. The soil medium beneath the foundation was modeled employing soil spring. The width and the thickness of the soil medium were taken as 1.5 times and 2 times the least width of the foundation which shows a negligible influence on the settlement and the contact pressure. The study primarily attempts to see the effect of soilstructure interaction on buildings resting on different 
types of non-cohesive soil, viz., soft, stiff, dense soil and rock. The details of different soil parameters are as tabulated in Table 3.3 .

TABLE 3.3: DETAILS OF SOIL PARAMETERS CONSIDERED (FEMA 273:1997[11] AND FEMA 356:2000[12])

\begin{tabular}{|c|c|c|c|c|c|c|c|}
\hline 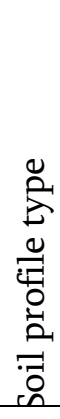 & 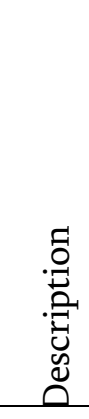 & $\begin{array}{l}\text { Shear } \\
\text { wave } \\
\text { veloc } \\
\text { ity } \\
(\mathrm{Vs}) \\
(\mathrm{m} / \mathrm{se} \\
\text { c) }\end{array}$ & 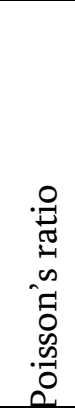 & $\begin{array}{l}\text { Unit } \\
\text { weig } \\
\text { ht }(\rho) \\
(\mathrm{kN} / \\
\mathrm{m} 3)\end{array}$ & $\begin{array}{l}\text { Shear } \\
\text { modu } \\
\text { lus } \\
(\mathrm{G}) \\
(\mathrm{kN} / \\
\left.\mathrm{m}^{2}\right)\end{array}$ & 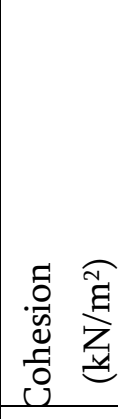 & 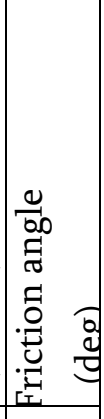 \\
\hline 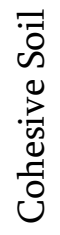 & Clay & 150 & 0.4 & 16 & 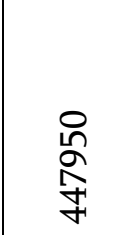 & 25 & 30 \\
\hline 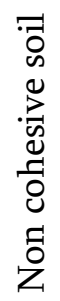 & $\begin{array}{l}\text { San } \\
\text { d }\end{array}$ & 600 & 0.3 & 20 & $\begin{array}{l}8 \\
8 \\
2 \\
\text { ని }\end{array}$ & 5 & 35 \\
\hline
\end{tabular}

\section{Modeling}

4.1 Introduction

In the current study, to depict the influence of soil structure interaction on the seismic response of a structure due to earthquake loading, a 11 storied $(\mathrm{G}+10)$ simple square building supported on individual foundation resting on stratified soil was selected. The building sections were modelled and analyzed for different configurations i.e., with fixed support and with SSI using finite element method ETAB 2016 subjected to Elcentro earthquake ground motion in the time domain. The deformations under seismic loading in the structure and by incorporating the effect of soil-structure interaction and fixed base condition were extracted, compared and discussed. Impact of variety of the parameters on different soil conditions like cohesive and non-cohesive are considered for which the buildings are modelled by alternate approaches, namely, (1) bare frame with fixed supports, (2) frames including with support accounting for soil-flexibility (SSI). Variations in the natural period are noted down for both support conditions and a comparative study has been done.

4.2 Defining the material properties, structural components and modeling the structure:

Beam, column and slab specifications are as follows:

Column - 400mm x 400mm

Beam - 400mm x 250mm

Slab thickness - $115 \mathrm{~mm}$

Brick wall thickness - 230mm

The plan of building is shown in fig. 4.1

Span of each beam is $4.5 \mathrm{~m}$ in X-direction and $\mathrm{Y}$ direction both.

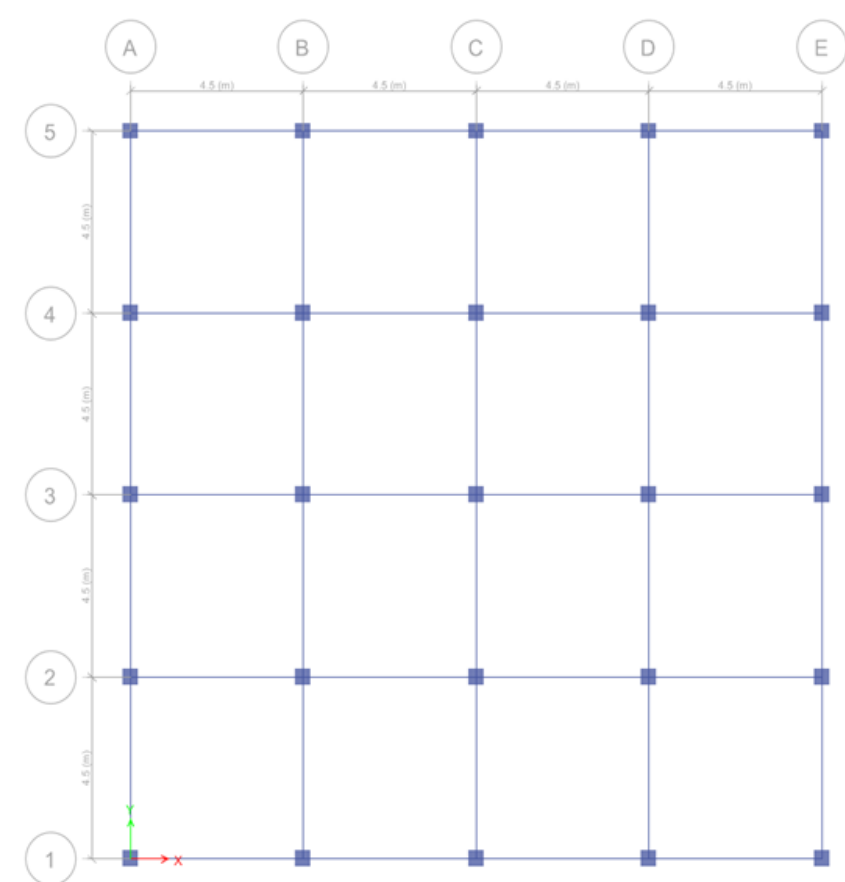

Fig. 4.1 Typical Plan of G+10 RCC building

The required material properties like mass, weight density, modulus of elasticity, shear modulus and 
design values of the material used can be modified as per requirements or default values can be accepted.

Beams and column members have been defined as 'frame elements' with the appropriate dimensions and reinforcement.

Soil structure interaction has been considered and the columns have been restrained in all six degrees of freedom at the base.

Slabs are defined as area elements having the properties of shell elements with the required thickness. Slabs have been modeled as rigid diaphragms.

\subsection{Assigning loads.}

After having modeled the structural components, all possible load cases are assigned. These are as follows:

\subsubsection{Gravity loads}

Gravity loads on the structure include the self-weight of beams, columns, slabs, walls and other permanent members. The self-weight of beams and columns (frame members) and slabs (area sections) is automatically considered by the program itself. The wall loads have been calculated and assigned as uniformly distributed loads on the beams.

Wall load = unit weight of brickwork $\mathrm{x}$ thickness of wall $\mathrm{x}$ height of wall.

Unit weight of brickwork $=20 \mathrm{KN} / \mathrm{m} 3$

Thickness of wall $=0.23 \mathrm{~m}$

Thickness of parapet wall $=0.23 \mathrm{~m}$

Wall load on roof level $=\quad 20 \times 0.23 \times 0.75=$

$2.50 \mathrm{KN} / \mathrm{m}$ (parapet wall height $=0.75 \mathrm{~m}$ )

Wall load on all other levels $=20 \times 0.23 \times 3=$ $13.8 \mathrm{KN} / \mathrm{m}$ (wall height $=3 \mathrm{~m}$ )

Live loads have been assigned as uniform area loads on the slab elements as per IS 1893 (Part 1) 2016 Live load on roof $=1.5 \mathrm{KN} / \mathrm{m}^{2}$
Live load on all other floors $=2.5 \mathrm{KN} / \mathrm{m}^{2}$

Floor Finish $=1.0 \mathrm{KN} / \mathrm{m}^{2}$

As per Table 10, Percentage of Imposed load to be considered in Seismic weight calculation, IS 1893 (Part 1) 2016, since the live load class is up to 3 $\mathrm{KN} / \mathrm{m} 2,25 \%$ of the imposed load has been considered.

\subsubsection{Defining load combinations:}

According to IS 1893 (Part 1) 2016 for the limit state design of reinforced and prestressed concrete structures, the following load combinations have been defined.

The basic load combinations given by the code as per clause 6.3.4.1 are as follows

$\begin{array}{ll}\text { 1. } & 1.2(\mathrm{DL}+\mathrm{LL} \pm(\mathrm{EQX} \pm 0.3 \mathrm{EQY} \pm 0.3 \mathrm{EQZ})) \\ \text { 2. } & 1.2(\mathrm{DL}+\mathrm{LL} \pm(\mathrm{EQY} \pm 0.3 \mathrm{EQX} \pm 0.3 \mathrm{EQZ})) \\ \text { 3. } & 1.5(\mathrm{DL} \pm(\mathrm{EQX} \pm 0.3 \mathrm{EQY} \pm 0.3 \mathrm{EQZ})) \\ \text { 4. } & 1.5(\mathrm{DL} \pm(\mathrm{EQY} \pm 0.3 \mathrm{EQX} \pm 0.3 \mathrm{EQZ}) \\ \text { 5. } & 0.9 \mathrm{DL} \pm 1.5(\mathrm{EQX} \pm 0.3 \mathrm{EQY} \pm 0.3 \mathrm{EQZ}) \\ 6 . & 0.9 \mathrm{DL} \pm 1.5(\mathrm{EQY} \pm 0.3 \mathrm{EQX} \pm 0.3 \mathrm{EQZ})\end{array}$

\subsubsection{Analysis of the structure}

Namely three types of analysis procedures have been carried out for determining the various structural parameters of the model. Here we are mainly concerned with the behavior of the structure under the effect of ground motion and dynamic excitations such as earthquakes and the displacement of the structure in the elastic range. The analyses carried out by Time History method.

Here we are primarily concerned with observing the deformations, forces and moments induced in the structure due to dead, live loads and earthquake loads. The load case 'Dead' takes care of the self-weight of the frame members and the area sections. The wall 
loads have been defined under a separate load case 'Wall' and the live loads under the case 'Live'. Analysis is carried out for all three cases for obtaining the above mentioned parameters.

Modal analysis is carried out for obtaining the natural frequencies, modal mass participation ratios and other modal parameters of the structure. Time history analysis of the eight models are done in the zone III where

\section{$\mathrm{Z}=0.16$ considering zone factor III}

$\mathrm{I}=1.0$ considering residential building.

$\mathrm{R}=5.0$ considering special $\mathrm{RC}$ moment resistant frame (SMRF)

$\mathrm{S}$ a $/ \mathrm{g}=$ By software

Time history analysis is carried out using the spectra for cohesive and non-cohesive soil as per IS 1893 (Part 1) 2016.

\subsubsection{Time history analysis in ETAB 2016}

* The step by step procedure is as follows Defining a time history function by adding a function from file. In our case, the Elcentro earthquake record of 1940 has been linked to the program.

* Defining a separate analysis case under the load type 'quake' with the appropriate analysis case type i.e. linear direct integration time history.

- Applying earthquake acceleration values from the defined time history function.

* Specifying the damping coefficients by calculating the mass and stiffness proportional coefficients as per the equations mentioned above or inputting the frequency or time periods of two consecutive modes of the structure in the same direction whereby the program itself calculates the required damping coefficients.
* Specifying a direct integration method in the program.

* In our case, we have adopted Newmark's direct integration method.

* Running the analysis.

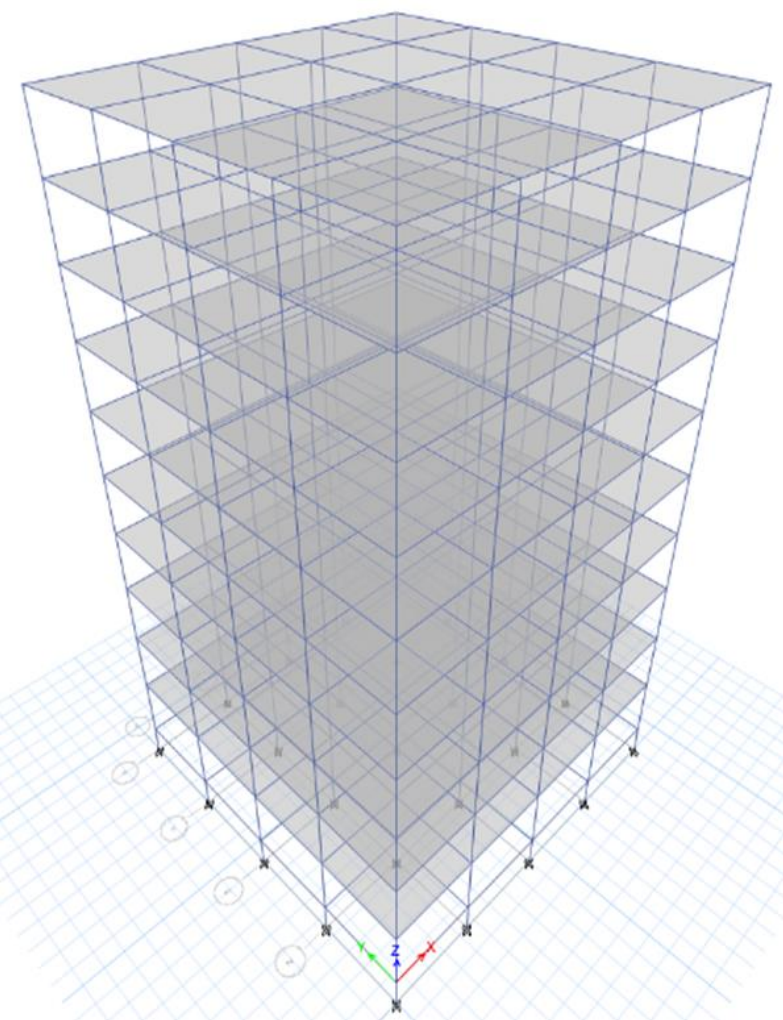

Fig 4.2 3D View of G+10 building

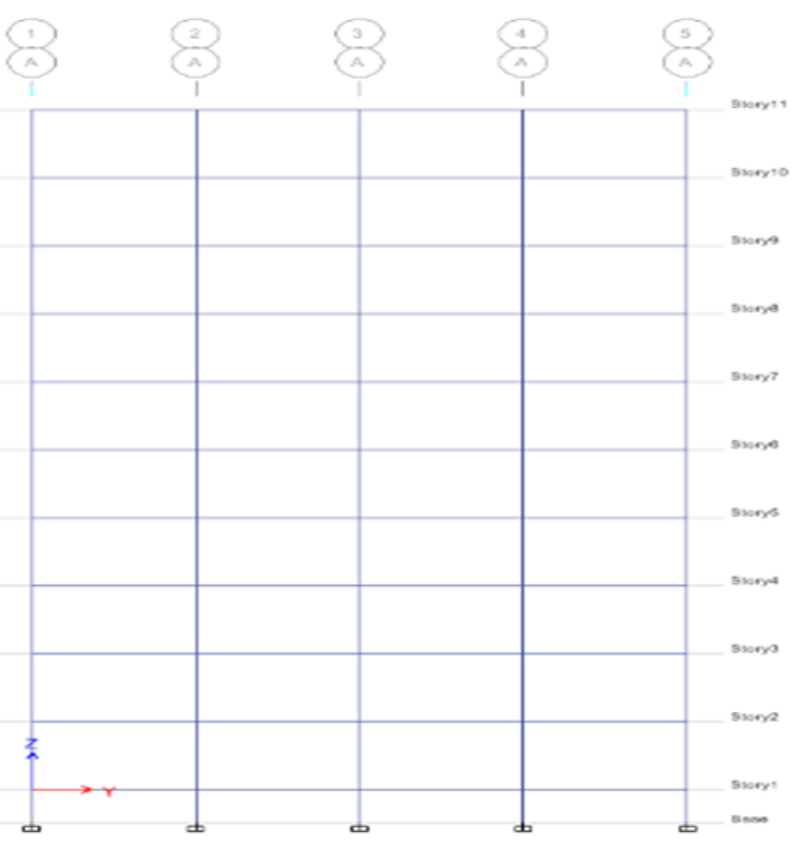

Fig. $4.3 \mathrm{G}+10$ building with Fixed Base 


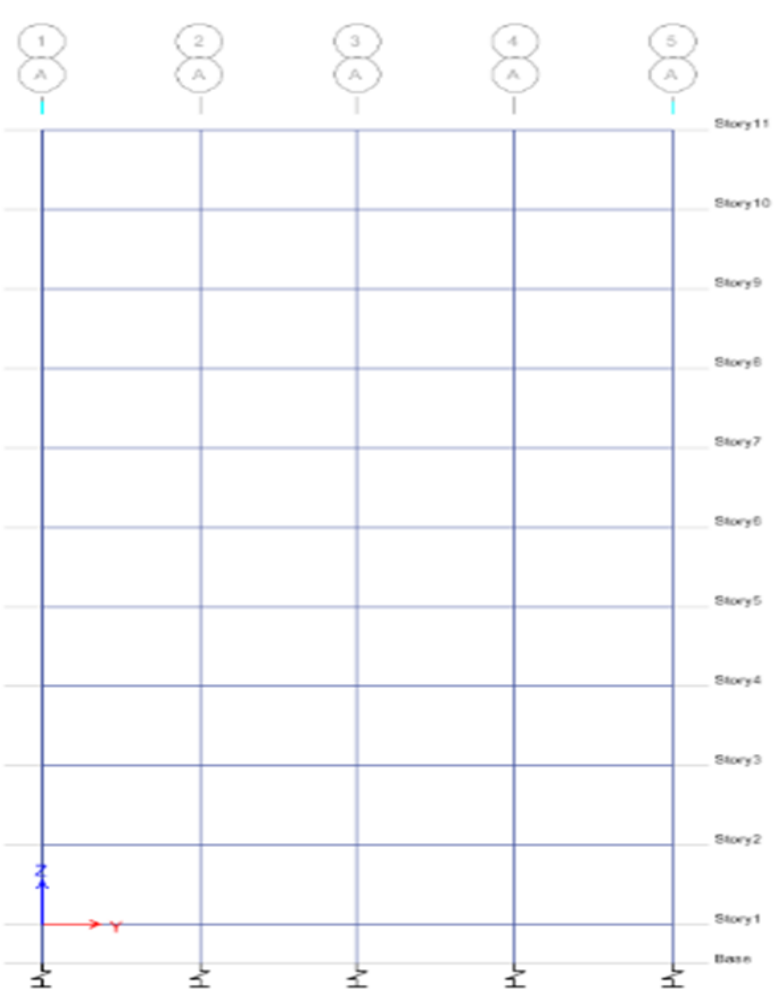

Fig. $4.4 \mathrm{G}+10$ building with SSI

TABLE 4.1: BASE SHEAR IN KN

\begin{tabular}{|l|l|l|}
\hline Soil media & Fixed Base & SSI \\
\hline Cohesive soil & 1700.9651 & 1717.78 \\
\hline Non-Cohesive soil & 1398.8714 & 1402.91 \\
\hline
\end{tabular}

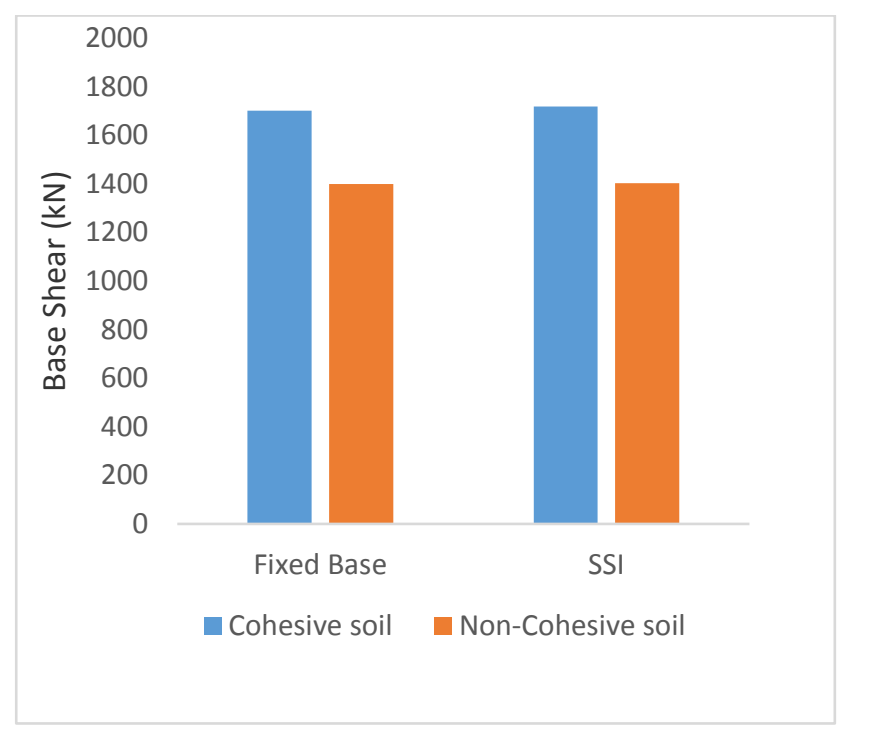

TABLE 4.2: MAXIMUM LATERAL DISPLACEMENT IN MM

\begin{tabular}{|l|l|l|}
\hline Soil media & Fixed Base & SSI \\
\hline Cohesive soil & 96.734 & 95.221 \\
\hline Non-Cohesive soil & 66.253 & 66.061 \\
\hline
\end{tabular}

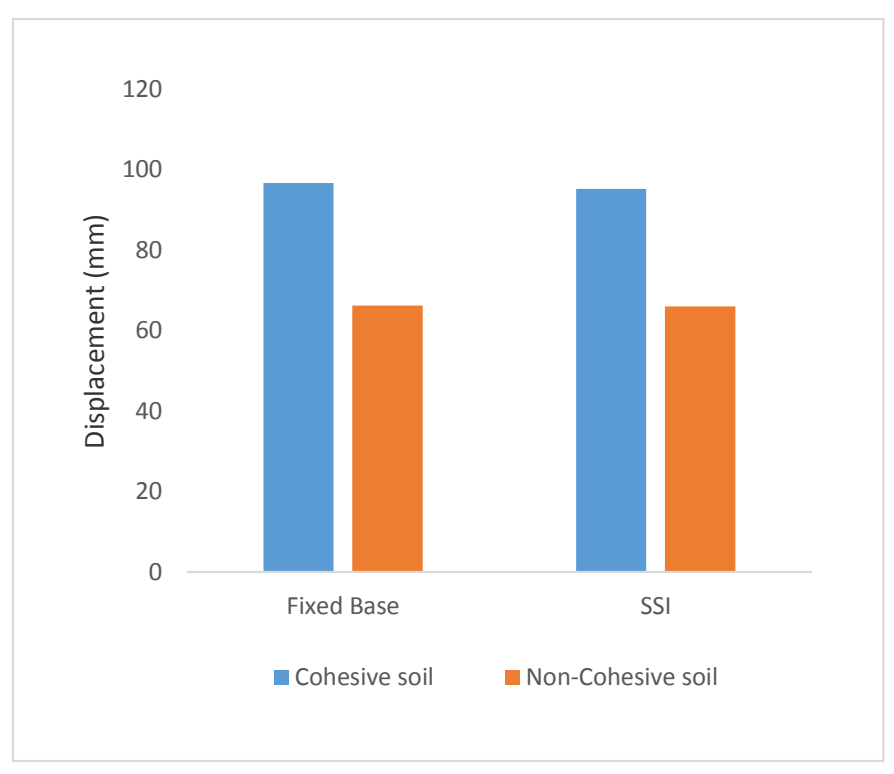

\section{v. CONCLUSION}

1. Base shear obtained for the fixed base condition in cohesive soil is $18 \%$ higher than non-cohesive soil.

2. Soil structure interaction in cohesive soil is $18 \%$ higher than non-cohesive soil.

3. The Maximum lateral displacement obtained for the Fixed Base and SSI in Cohesive soil is 31\% higher than Non-cohesive soil.

4. This variation increases with increase in flexibility of soil.

5. Cohesive soil shows higher displacement or result than non-cohesive soil.

6. Study done clearly shows that base support condition has an impact on the behavior of structure which can be clearly observed from 
linear static analysis. Soil structure interaction should be considered in analysis.

7. Finally it concludes that the always consideration of fixed base while designing the building is not correct.

8. Finally, it can be concluded that although conventional design procedure omitting SSI is conservative it is required to ensure the structural safety of buildings resting over soft soil due to lateral deflection.

\section{ACKNOWLEDGMENT}

I would like to show my admiration and gratitude to all the concerns who helped and facilitated me whenever I required, during this paper completion, particularly Mrs Tushar G. Shende, my guide for his unconditional support.

\section{REFERENCES}

[1]. IS: 1893 (Part 1) - 2016; "Criteria for Earthquake Resistant Design of Structures - general provisions and buildings"; Bureau of Indian Standards, New Delhi.

[2]. Jagadish ponraj Nadar, "Soil Structure Interaction of Tall Buildings ", International Journal of Computer Applications (0975 - 8887) International Conference on Quality Upgradation in Engineering, Science and Technology (ICQUEST2015)

[3]. Dange Swati, "Effect of soil structure interaction (SSI) on the analysis and design of RC framed buildings" | IJMER | ISSN: 2249-6645 www.ijmer.com | Vol. 6 | Iss. 5 | May 2016 | 44 |

[4]. B. Ravi Sankar, "Designing an Isolated Footing in Cohesive and Non-Cohesive Soils", IOSR Journal of Mechanical and Civil Engineering (IOSR-JMCE) e-ISSN: 2278-1684,p-ISSN: 2320334X, Volume 13, Issue 1 Ver. VI (Jan- Feb. 2016), PP 68-71
[5]. Basavanagowda G. M G. M Basavanagowda, Govindaraju .L, "Influence of Stratified Soil on Seismic Response of Pile Supported Building",International Journal of Advance Research, Ideas and Innovations in echnology 2017.

[6]. S.A.Rasal, Chore H.S, P.A.Dode, "INTERACTION OF FRAME WITH PILE FOUNDATION", IOSR Journal of Mechanical and Civil Engineering (IOSR-JMCE) ISSN: 22781684, PP: 59-62 www.iosrjournals.org Second International Conference on Emerging Trends in Engineering (SICETE)

[7]. Janardhan Shanmugam," Analysis of Soil Structure Interaction in Framed Structure", International Journal of Computer Applications (0975 - 8887) International Conference on Quality Up-gradation in Engineering, Science and Technology (ICQUEST2015) 11

[8]. Preeti Codoori," Seismic Analysis of Soil-pile Interaction under Various Soil Conditions", International Journal of Applied Engineering Research ISSN 0973-4562 Volume 12, Number 18 (2017) pp. 7566-7571 (C) Research India Publications. http://www.ripublication.com

[9]. Bhavani Shankar , Dheekshith K,"COMPARATIVE STUDY ON SEISMIC ANALYSIS OF SOIL STRUCTURE INTERACTION WITH VARIOUS SOIL PROPERTIES BY VARYING FLOOR LEVELS", International Research Journal of Engineering and Technology (IRJET) e-ISSN: 2395 -0056 Volume: 03 Issue: 10 | Oct -2016 www.irjet.net p-ISSN: 2395-0072

[10]. Chinmayi H.K., Jayalekshmi B.R.,"Soil-Structure interaction effects on seismic response of a 16 storey RC framed building with shear wall", American Journal of Engineering Research (AJER),2013, e-ISSN : 2320-0847 p-ISSN : 2320- 
0936 Volume-2 pp-53-58 www.ajer.org Research Paper Open Access

[11]. Bhattacharya. K, and Dutta, S.C and Rana Roy, "Seismic Design Aids for Buildings incorporating Soil-flexibility", Journal of Asian Architecture and Building Engineering, November 2006, pp 341-348.

[12]. Ravikumar C M, Babu Narayan K, Sujith B and Venkat Reddy, "Effect of Irregular Configurations on Seismic Vulnerability of RC Buildings", Department of Civil Engineering, National Institute of Technology, Surathkal.

[13]. Bhattacharya. K, and Dutta, S.C, "Assessing lateral period of building frames incorporating Soil-flexibility", Journal of Sound and Vibration, Dec-2004, pp 795-821.

[14]. Prabhat Kumar A.D. Pandey, and Sharad Sharma, "Seismic soil- structure interaction of buildings onhill slopes", Journalof Civiland Structural Engineering, 2011.

[15]. Kraus \& D. Dzakic, "Soil-structure interaction effects on seismic behavior of reinforced concrete frames", JosipJurajStrossmayer University of Osijek, Faculty of Civil Engineering Osijek, Croatia

[16]. Jenifer, Priyanka,R.M. and Anand,N.2012, "Effect of lateral force on tall buildings with different type of irregularities.", In Proceedings of the INCACMA Conference on Advances in Construction, Manufacturing and Automation Research

[17]. Dr. S. A. Halkude, Mr. M. G. Kalyanshetti and Mr. S. H. Kalyani, "Soil Structure Interaction Effect on Seismic Response of R.C. Frames with Isolated Footing", Civil Engg. Dept. Walchand Institute of Technology, Solapur, Solapur University, India Vol. 3 Issue 1, January - 2014.

\section{Cite this article as :}

Aniket S. Deshmukh, Dr. Tushar G. Shende, "Seismic Response of Multistoried Building Considering Effect of Cohesive and Non-Cohesive Soil", International Journal of Scientific Research in Science and Technology (IJSRST), Online ISSN : 2395-602X, Print ISSN : 2395-6011, Volume 6 Issue 2, pp. 744-755, March-April 2019. Available at doi : https://doi.org/10.32628/IJSRST1962165 Journal URL : http://ijsrst.com/IJSRST1962165 